\title{
Time-Lapse In Vivo Imaging of Corneal Angiogenesis: The Role of Inflammatory Cells in Capillary Sprouting
}

Beatrice Bourghardt Peebo, Per Fagerholm, Catharina Traneus-Rockert and Neil Lagali

\section{Linköping University Post Print}

N.B.: When citing this work, cite the original article.

Original Publication:

Beatrice Bourghardt Peebo, Per Fagerholm, Catharina Traneus-Rockert and Neil Lagali, Time-Lapse In Vivo Imaging of Corneal Angiogenesis: The Role of Inflammatory Cells in Capillary Sprouting, 2011, INVESTIGATIVE OPHTHALMOLOGY and VISUAL SCIENCE, (52), 6, 3060-3068.

http://dx.doi.org/10.1167/iovs.10-6101

Copyright: Research in Vision and Opthalmology http://www.arvo.org/

Postprint available at: Linköping University Electronic Press http://urn.kb.se/resolve?urn=urn:nbn:se:liu:diva-69178 


\section{Time-lapse in vivo imaging of corneal angiogenesis: the role of inflammatory cells in capillary sprouting}

Beatrice Bourghardt Peebo ${ }^{1}$, Per Fagerholm ${ }^{1}$, Catharina Traneus-Röckert ${ }^{2}$ and Neil Lagali ${ }^{1}$

${ }^{1}$ Department of Clinical and Experimental Medicine, Faculty of Health Sciences, Linköping University, 58183 Linköping, Sweden

${ }^{2}$ Department of Pathology, Linköping University Hospital, 58185 Linköping, Sweden

Supported by grants from the Kronprinsessan Margaretas Arbetsnämnd (BBP and NL), The Swedish research Council, County Council of Östergötland (PF) and a Marie Curie International Research Fellowship (NL)

Disclosure: B Bourghardt Peebo, None; P Fagerholm, None; C. Traneus-Röckert, None; N. Lagali, None.

Word count: 3882

Corresponding author and reprint request:

Neil Lagali

Department of Clinical and Experimental Medicine

Faculty of Health Sciences

Linköping University

58183 Linköping

Sweden

Tel: +46 101034658

Fax: +46 101033065

email: neil.lagali@liu.se 


\section{ABSTRACT:}

Purpose: To elucidate the temporal sequence of events leading to new capillary sprouting in inflammatory corneal angiogenesis.

Methods: Angiogenesis was induced by corneal suture placement in Wistar rats. The inflamed region was examined by time-lapse in vivo confocal microscopy for up to 7 days. At 6h, 12h, and day 1, 2, 4 and 7, corneas were excised for flat-mount immunofluorescence with primary antibodies for CD31, CD34, CD45, CD11b, CD11c, Ki-M2R, NG2 and $\alpha$-SMA. From day $0-4$, the in vivo extravasation and expansion characteristics of single limbal vessels were quantified.

Results: Starting hours after induction and peaking at day 1, CD45+CD11b+ myeloid cells extravasated from limbal vessels and formed endothelium-free tunnels within the stroma en route to the inflammatory stimulus. Limbal vessel diameter tripled on day $2-3$ as vascular buds emerged, which transformed into perfused capillary sprouts less than one day later. A subset of spindle-shaped CD11b+ myeloid-lineage cells, but not dendritic cells or mature macrophages, appeared to directly facilitate further capillary sprout growth. These cells incorporated into vascular endothelium near the sprout tip, co-expressing endothelial marker CD31. Sprouts had perfusion characteristics distinct from feeder vessels and many sprout tips were open-ended.

Conclusions: Time-lapse in vivo corneal confocal microscopy can be used to track a temporal sequence of events in corneal angiogenesis. The technique has revealed potential roles for myeloid cells in promoting vessel sprouting in an inflammatory corneal setting. 


\section{Introduction}

Angiogenesis, the phenomenon of new vessel formation from pre-existing vessels, is implicated in a host of pathophysiologic processes such as cancer, chronic inflammatory diseases, and sight-threatening conditions of the retina and cornea. The cornea, in particular by virtue of its anatomic accessibility, normal avascularity and transparency, and its robust angiogenic response under appropriate stimulation - has been utilized extensively to study angiogenesis, as a phenomenon of broad interest ${ }^{1-5}$ and for its direct application to corneal pathology such as transplant rejection ${ }^{6-8}$ and viral infection ${ }^{9-11}$. Pathologic new vessel invasion and the resulting loss of corneal immune privilege is often accompanied by inflammation and can result in corneal tissue damage, loss of transparency, and reduced vision. The most common mechanism whereby these new, angiogenic vessels emerge is by the formation of 'sprouts' directly from the vascular endothelium of existing parent vessels located in the limbus ${ }^{12}$. Although this sprouting process is fundamental to angiogenesis, there is surprisingly little information available about the detailed, temporal sequence of events at the cellular level leading to sprout formation.

In this study, we sought to investigate the evolution of angiogenic sprouts in a sutured cornea, a model for inflammation-associated angiogenesis in situ. Using a clinical in vivo corneal confocal microscope for non-invasive and label-free imaging, we tracked the same tissue region and monitored single corneal vessels over a period of days, to study the tissue changes leading to angiogenic sprout formation. Subsequent ex vivo immunostaining of the same tissue and imaging with a similar orientation and resolution enabled direct in vivo/ex vivo comparison. By this manner, interpretation of in vivo observations could be aided by the molecular-level specificity of cell surface markers ${ }^{13}$. 
Inflammatory cells are known to infiltrate tissue at local sites of vascular remodeling ${ }^{14-16}$, where they secrete pro-angiogenic factors and metalloproteinases ${ }^{17-23}$. Inflammatory cells (notably monocytes) have been shown to have trans-differentiation potential, expressing cell surface markers and phenotypic characteristics of vascular endothelium in a pro-angiogenic environment $^{24-27,22}$. Moreover, in non-ocular models, monocytes have been detected within angiogenic vessel walls ${ }^{15,16}$. While the paracrine contribution of inflammatory cells to angiogenesis is gaining increasing attention, there is comparatively little knowledge about the parallel spatio-temporal roles of these cells in the vascular remodeling process, particularly in the cornea. We therefore further sought to examine the relationship of infiltrating inflammatory cells to existing and new vessels in our model.

Materials and Methods:

\section{Rat model of suture-induced inflammatory corneal neovascularisation}

Fourteen twelve- to sixteen-week-old male Wistar rats weighing 200 to $400 \mathrm{~g}$ (Scanbur AB, Sollentuna, Sweden) were used. All animals were treated following ARVO guidelines for the Use of Animals in Ophthalmic and Vision Research. With approval from the Linköping regional animal ethics review board, rats were anesthetized and a corneal stromal suture was placed $1.5 \mathrm{~mm}$ from the temporal limbus as previously described ${ }^{13}$. A second stromal suture was placed at the 3 o'clock position, $1.5 \mathrm{~mm}$ from the nasal limbus, to provide additional tissue samples for ex vivo analysis. Left eyes served as negative controls. At 0,6 and 12h and day $1,2,3,4,5$ and 7 after the initial surgery, rats were anesthetized using intraperitoneal injection of dexmeditomedine (Orion Pharma AB, Sollentuna, Sweden) and xylazine (Pfizer $\mathrm{AB}$, Sollentuna, Sweden) and laser scanning in vivo confocal microscopy of the corneas was performed after topical administration of $1 \%$ tetracaine. The number of rats anesthetized at each time point was as follows: 0h (4), 6h (4), 12h (3), day1 (6), day 2 (5), day 3 (6), day 4 (7) 
day 5 (3) and day 7 (6). Examination lasted for a maximum of 15-20 minutes, during which time corneas were hydrated with Viscotears (Novartis Healthcare A/S, Copenhagen, Denmark). Anaesthesia was thereafter immediately reversed by subcutaneous injection of 0.1 $\mathrm{ml}$ atipamezol (Orion Pharma AB, Sollentuna, Sweden). Following in vivo microscopy at 6 and 12h and day 1,2, 4 and 7; one, one, one, one, four, and six animals were euthanized, respectively, by intracardiac injection of $100 \mathrm{mg} / \mathrm{kg}$ pentobarbital sodium (Apoteket $\mathrm{AB}$, Linköping, Sweden). The entire cornea with scleral rim was excised and nasal and temporal portions were prepared for flat-mounting.

\section{In vivo confocal microscopy}

With rats under general anaesthesia, corneas were examined by laser-scanning in vivo confocal microscopy (IVCM). The equipment and technique have been described in detail elsewhere ${ }^{13}$. Once the suture was located, the field of view was translated temporally to locate the limbal region. Axial depth was adjusted to visualize the blood vessels at the limbal arcade. Digital images were recorded at 5 frames/s, and the probed region was adjusted in lateral, transverse, and axial directions during image capture to locate and follow the path of limbal vessels and angiogenic sprouts towards the suture area. A typical examination consisted of 10 to 40 image sequences with each sequence containing 100 successive digital image frames. Sequences could be analyzed frame-by-frame or in video mode, played at the image acquisition rate. In total 62500 images were captured for analysis. Time-lapse imaging of the same microscopic corneal region, in the same animal, was performed under repeated anaesthesia. Time-lapse sequences were obtained during the periods of 0 to 2 days $(0,6 \mathrm{~h}, 12 \mathrm{~h}$, 1 day, 2 days) and 0 to 4 days ( $0,1,2,3,4$ days). In some cases, corneas were examined up to 7 days after suture placement. Identification of the same vessels at different times was achieved by comparison of limbal vessel characteristics with previously stored images. 


\section{Immunofluorescence}

Briefly, frozen corneas were thawed and rinsed in PBS; fixed in acetone; rinsed in PBS 3 times; blocked in 10 \% normal donkey serum (Jackson ImmunoResearch Europe, Newmarket, UK); and incubated with primary antibodies overnight. The next day, samples were washed 3 times in PBS, blocked in $10 \%$ serum and incubated with secondary antibodies overnight. For double immunostaining, this procedure was repeated. Primary antibodies included panendothelial marker CD31/PECAM-1 (Santa Cruz Biotechnology Inc. Santa Cruz, CA, USA), myeloid lineage marker CD11b (Santa Cruz), dendritic cell marker CD11c (Abcam PLC, Cambridge, UK), hematopoietic marker CD34 (R\&D Systems, Minneapolis, MN, USA), panleukocyte marker CD45 (Millipore AB, Solna, Sweden ), mature pan-macrophage marker for rat Ki-M2R (Abcam), mature pericyte marker NG2 (Millipore) and smooth muscle cell marker $\alpha$-SMA (Dako Denmark, Glostrup, DK). Secondary antibodies (Jackson) included Cy3, FITC, Dylight 549, Dylight 649 and Dylight 488. All imaging was performed using a laser-scanning confocal fluorescence microscope (Nikon Eclipse E600) equipped with 20x/0.75 NA, and 40x/1.30 NA and 60x/1.40 NA oil-immersion objective lenses (Nikon). Samples were scanned under single or dual laser excitation and a digital camera was used to record images. In all cases, control samples were used and omission of the primary antibody eliminated cell-specific staining.

\section{Cell and vessel quantification and statistical analysis}

In vivo image frames with distinct blood vessels in the limbal region were selected from examinations of the same corneas at day $0-4$. Within each image frame, the diameter of limbal vessels (typically one or two per frame) was measured at two to three locations along the vessel (spaced 100-150 $\mu \mathrm{m}$ apart). A manual line tool was used for the measurements, and a single observer performed measurements using ImageJ software (developed by Wayne 
Rasband, National Institutes of Health, Bethesda, MD; available at http://rsb.info.nih.gov/ij/index.html). Statistical analysis of limbal blood vessel diameter was performed using an independent t-test where values were normally distributed and the nonparametric Mann-Whitney rank sum test otherwise. Normality was determined by the Kolmogorov-Smirnov test. All comparisons were performed using statistical software (SigmaStat, Syastat Software Inc. Chicago, IL, USA) and a two-tailed value of $\mathrm{P}<0.05$ was considered statistically significant.

For cell counting, in vivo frames from day $0-4$ depicting the identical limbal region in a given cornea were selected. Inflammatory cells were counted within a box (measuring 150 $\mu \mathrm{m} \times 300 \mu \mathrm{m})$ placed in each image at the same location. The left side (long edge) of the box just touched the limbal vessel at the vessel-stroma interface. Cells touching the bottom and left edges of the box were counted, while those touching the top and right edges were excluded. Cells were counted by two independent observers, with standardized brightness and contrast levels. Cells were identified as discrete, hyper-reflective, round or spindle-shaped structures. The mean cell count of both observers was reported, and the Bland-Altman method was used to determine the $95 \%$ limits of agreement between observers ${ }^{28}$.

\section{Results}

\section{Extravasated cell patterning of the extracellular matrix by tunnel formation}

Six hours after suture placement, inflammatory cells extravasated from limbal vessels had traversed a distance of $1.5 \mathrm{~mm}$ through the stromal extracellular matrix (ECM) to reach the suture in 3 of 4 corneas (in the remaining cornea, cells travelled $1 \mathrm{~mm}$ in $6 \mathrm{~h}$ ). Extravasated cells in close proximity to parent limbal vessel walls were round with a hyper-reflective nucleus, while cells in the stroma had both round and spindle-shaped forms (Fig.1). In one 
cornea at $6 \mathrm{~h}$, a hypo-reflective, tunnel-like formation was observed emanating from a limbal vessel; the center of the tunnel was occupied by hyper-reflective cells (Fig. 1B). Both rounded and spindle-shaped cells of the stromal infiltrate expressed the myeloid-lineage marker

CD11b. These cells often appeared to migrate through the stroma following the same paths, suggesting migration within tunnels (Fig. 1D). The first cells to reach the inflammatory stimulus were rounded, forming long, string-of-pearl configurations, indicative of cells occupying a single tunnel (Fig. 1E). Cells further from the suture were mostly spindle-shaped, arranged in multi-cellular 'chains', and were oriented with their long axis towards the suture (Fig. 1F).

\section{Cellular composition of the inflammatory infiltrate}

To characterize the cells of the inflammatory infiltrate, corneal tissue observed in vivo was subsequently full-thickness flat-mounted to preserve spatial orientation and morphology. Immunofluorescent labeling of flat mounts revealed that the round and spindle-shaped cells observed in vivo were CD11b+CD45+ confirming their leukocytic, myeloid lineage (Fig. 2A, B). To determine whether the myeloid cell population consisted of sub-populations of cells committed to dendritic or macrophage lineages, dual marker expression was evaluated with CD11b/CD11c and CD11b/KiM2R, respectively. The infiltrate was composed of subpopulations of CD11b-CD11c+, CD11b+CD11c- and CD11b+CD11c+ cells (Fig. 2C, D). CD11c+ cells (both CD11b+ and CD11b-) were irregular or dendriform in shape, and were randomly oriented and distributed within the infiltrate, while CD11b+CD11c- cells were predominantly round or spindle-shaped and were frequently found in organized, linear patterns oriented in the direction of the suture. A delayed infiltration of the stroma by mature macrophages was noted (Fig. 3). At day 2, CD11b+KiM2R+ mature macrophages were abundant in the conjunctiva, but only a few were found in the stroma (Fig. 3A, B). Mature 
macrophages were larger and more irregularly-shaped than CD11b+KiM2R-cells, with a seemingly random orientation and distribution. By day 7, mature macrophages infiltrated the stroma in substantial numbers and accumulated at the suture (Fig. 3C, D). A CD11b+KiM2R+ macrophage population around the suture had a rounded in vivo appearance, with hyporeflective center, differing from the smaller, CD11b+KiM2R- spindle-shaped cells. To determine whether hematopoietic stem cells were present within the inflammatory infiltrate, samples were co-stained with CD11b/CD34 at day 4. No co-staining of CD11b and CD34 was found, nor could any discrete CD34+ cells be detected in the stroma, although vascular endothelium of mature conjunctival vessels was CD34+ (results not shown).

\section{Single-vessel time course of early extravasation and parent limbal vessel expansion}

Daily in vivo localization and non-invasive imaging of the same limbal vessels was achieved over a 4-day period (Fig. 4). Cells proximal to the same limbal vessel were counted from in vivo confocal image frames taken on successive days in three corneas. A peak in cell extravasation occurred at day 1 , followed by a decline at day 2 (Fig. 5). This peak was evident in vivo, with many cells present near limbal vessel walls during the first day. On day 2 , extravasation diminished and limbal vessel diameter increased. Limbal vessel diameter approximately doubled during the first day, and peaked at day $2-3$, when median vessel

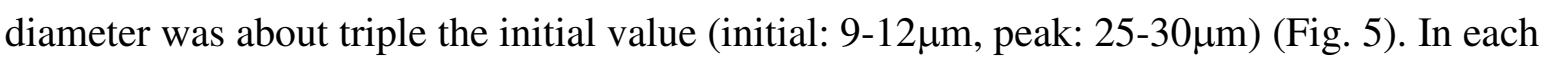
of three corneas, peak vessel diameter was significantly greater than the value at day $1(\mathrm{P}<$ 0.001). Following maximal vessel expansion, a reduction in diameter occurred at day $3-4$.

\section{Maximal parent vessel expansion and vascular bud formation}

At the time of maximal limbal vessel expansion, localized protrusions in the vessel wall (vascular buds) were observed in vivo (Fig. 6). Buds had a variable appearance, ranging from 
large, perfused buds along the path of blood flow to smaller, discrete buds protruding from vessel walls perpendicular to the direction of flow, and not visibly perfused. When limbal vessels with buds observed in vivo were located after immunostaining, vessel and bud walls were found to be CD11b-CD31+ (Fig. 6). Cells observed within the vessel lumen and in the stroma outside the bud were CD11b+CD31- , and no extra-vascular cell stained CD31+. CD11b+ cells with a stromal location did not appear to interact directly with the vascular bud.

\section{Vascular buds rapidly form capillary sprouts with distinct perfusion characteristics}

Limbal vessels with vascular buds were monitored daily in vivo to observe the process of capillary sprout formation. Reduced inflammatory cell density near parent limbal vessels at day 2 coincided with massive vessel diameter expansion and bud formation (Fig. 7). In one case, two adjacent vascular buds at day 2 each evolved into a perfused capillary sprout less than a day later (Fig. 7 B, C). Invariably, the first perfused sprouts arose from limbal vessel buds in vessels at the 9 o'clock position at day $3-4$. In vivo, the new capillary sprout lumen did not contain freely-flowing blood laden with hyper-reflective erythrocytes (as with mature vessels), but was perfused with a slow-moving fluid derived from feeder blood vessels, harboring round, hyper-reflective cells and long cord-like structures (Fig. 8, Movie S1). In some instances, the flow in feeder blood vessels appeared to bypass the sprout fluid without interaction, temporarily isolating the perfused sprouts from the circulation (Fig. 8F).

Additionally, the sprout tip region often appeared open-ended in vivo, with cord-like material and cells appearing to leave the lumen to enter the stroma (Fig. 8A-D). Immunofluorescent staining revealed CD11b+CD31- cells and cord-like structures within the lumen, in some cases appearing to emanate from open-ended sprout tips (Fig. 8C). Blood vessel sprouts were distinguished from possible lymphangiogenic sprouting by the direct connection to feeder 
blood vessels, an observable sprout wall, and constant vessel diameter in sprout stalks, in addition to their early emergence compared to lymphangiogenic vessels in our model. ${ }^{13}$

\section{Myeloid cell organization during capillary sprout growth}

During the period of sprout growth towards the inflammatory stimulus from day $3-7$, hyperreflective spindle-shaped cells aligned parallel to sprout walls and extended beyond the sprout tip into the stroma (Fig. 9A,B). Spindle-shaped cells also appeared in close contact to, or within, the sprout endothelial wall (Fig. 9C). Immunostaining revealed that some spindleshaped CD11b+ cells were incorporated into the vascular endothelium of advancing sprouts at day 7 (Fig. 9 D-F). Vascular endothelium of sprout tips at day 7 was CD11b(weak+)CD31+ or CD11b+CD31+ (Fig. 9G-I). In addition, at day 7 a population of CD11b+ cells in the stroma surrounding the tip region co-stained for CD31 (Fig. 9 G-I). At high magnification, fine, CD31+ extensions were observed at sprout tips, projecting into the surrounding matrix, in some cases appearing connected to cells strongly expressing both CD11b and CD31.

\section{The maturing endothelium of angiogenic capillary sprouts}

In contrast to cells near the sprout tip region, cells surrounding mature sprout stalks at day 7 (those closer to the limbal region) were $\mathrm{CD} 11 \mathrm{~b}+\mathrm{CD} 31$ - while stalk endothelium itself was CD11b-CD31+ (Fig. 10). Along with CD31, sprout stalks expressed CD34, but expression of CD34 was weak on sprout tip endothelium at day 4. By day 7, the majority of vessels were pericyte-covered, expressing both NG2 and $\alpha$-SMA (Fig. 11), while earlier expression of these markers at day 2 was negative (results not shown). No discrete NG2+ or $\alpha$-SMA+ cells were observed in the limbus or stroma separated from vessel walls at day 2 or day 7; however, some sprout stalks at day 7 were closely flanked by CD11b+ cells, with a morphology suggestive of pericytes or their progenitors, ${ }^{29,30}$ prior to vessel attachment (Fig. 11F). 


\section{Discussion}

A technique of time-lapse, in vivo imaging has been used to investigate the cellular sequence of events leading to sprouting angiogenesis. A major finding in this study was evidence for a multiplicity of roles played by a subset of $\mathrm{CD} 11 \mathrm{~b}+$ myeloid-lineage cells in the process of inflammatory sprouting angiogenesis in the cornea. These myeloid cells appeared to prepattern the ECM, direct the growth of sprouts, and seemed to incorporate into sprout tip endothelium. After the initial influx of inflammatory cells, many of these CD11b+ cells were spindle-shaped, distinctly differing both morphologically and in marker expression from cells committed to dendritic and macrophage lineages. The round and spindle-shaped CD11b+ cells may be neutrophils and monocytes, or distinct monocyte subsets ${ }^{25}$. Neutrophils are known to comprise the bulk of the early infiltrate in corneal inflammation ${ }^{31-33}$, and have been shown to have a peak influx into the cornea within one day after wounding ${ }^{31}$. Monocytes are also present within the infiltrate and have been shown to have a direct contribution to angiogenesis in numerous studies ${ }^{14-16,21,22,34-36}$. Notably, when cultured in the presence of angiogenic growth factors, monocytes have been shown to develop a spindle shape ${ }^{24,25}$ and in matrigel, monocytes have been reported to aggregate into cord and tubular like structures ${ }^{24}$. Future studies using our model with markers such as Gr-1 and CD14 could enable a differential analysis of the contribution of monocyte and neutrophil subpopulations in vivo. The concomitant appearance of both cell types, however, is $\mathrm{known}^{33,37}$, and it has been noted that these cell types may cooperate synergistically during inflammation ${ }^{37}$.

The endothelium-free tunnels we observed appeared similar to tunnels induced in matrigel and myocardial tissue following chemotactic and pro-angiogenic factor stimulation ${ }^{19,22,38}$. In one report ${ }^{22}$, in a model likely representing a parallel angiogenesis/vasculogenesis, several cell types including endothelial progenitors were found within tunnels after one to four weeks, 
raising the possibility that such cells may assist in the transformation of tunnels into functional capillaries. In this study, CD11b+CD45+ monocyte/neutrophils formed tunnels within hours after stimulation, but no dendritic cells, mature macrophages, CD31+ or CD34+ cells were found occupying tunnels during the first days after their formation. In the early phase of sprouting in our model, a subset of CD11b+ cells may have played a progenitor-like role due to their appearance within tunnels, columnar arrangement, close proximity to the advancing sprout tip, and co-expression of CD31 at the sprout tip region. Examining the expression of additional endothelial-lineage and progenitor cell markers would allow a closer investigation of the progenitor-like nature of the observed cells.

The early tunnels observed here, likely created by infiltrating cell migration, seemed to provide a patterned degradation of the ECM. This pre-patterning, before sprouting, may have facilitated the later invasion of actual capillary sprouts. This hypothesis is supported by our in vivo observations of sprout tips extending towards channels occupied by linear columns of cells. In addition to facilitating new blood vessel sprouting, we suspect that patterning of ECM by tunnels may also facilitate lymph vessel invasion. Studies demonstrating the suppression of both blood and lymph vessel invasion after local depletion of CD11b+ cells in a corneal inflammatory model ${ }^{21,39}$ underscore the key role of a CD11b+ cell population in angiogenesis. Along with pro-angiogenic factor secretion by these cells ${ }^{17-23}$, ECM patterning by tunnel formation may be an additional mechanism promoting the rapid influx of neovessels in inflammation.

In vivo observations in our model revealed a dramatic limbal vessel expansion. Subsequent vessel constriction, coinciding with the emergence of sprouts from vascular buds, indicates a burst-like process of capillary sprout formation. Interestingly, from the time of initial stimulation to the formation of the first capillary sprouts, no discrete CD31+ cells were 
observed in the stroma while vascular bud endothelium was CD11b-, suggesting that the vascular endothelium of newly formed sprouts did not originate from the extravasated inflammatory cell population but instead from proliferation of existing endothelium ${ }^{12}$. By contrast, after capillary sprouts were formed, a population of cells in the stroma co-expressing CD31 and CD11b, in close proximity to sprout tips, may have contributed, directly or indirectly, to their subsequent growth. In addition, some sprout tips appeared to eject CD11b+ cord-like material and cells into the stroma; the contribution of these cells to sprout growth remains unknown, but suggests an additional population of circulation-derived myeloidlineage material available for this purpose ${ }^{15}$. Sprout tips have been shown to be guided by projections (or filopodia) sensitive to a VEGF-A gradient ${ }^{40}$. Our observations of sprout tip projections attached to distal CD11b+CD31+ cells suggests that some myeloid-lineage cells may incorporate into the advancing sprout tip, in addition to secreting or responding to proangiogenic factors. Expression of CD11b on sprout tip endothelium (but not older sprout stalk endothelium near the limbus) provides additional evidence of trans-differentiation of CD11b+ cells into mature vascular endothelium during the sprout growth phase. The transdifferentiation potential of myeloid cells is supported by several recent studies ${ }^{22,24-27}$. Moreover, it has been proposed that monocytes trans-differentiating into vascular endothelium may serve an endothelial progenitor cell function ${ }^{26,41}$. Further studies are required to determine the specific activity of the population of CD11b+CD31+ cells we observed.

Evaluation of marker expression on sprout tips was suggestive of a shift in expression from myeloid to hematopoietic markers in the maturing sprout endothelium, a concept proposed by others ${ }^{22,42}$. We could find no evidence for the existence of CD34+ hematopoietic-lineage cells within the inflammatory stromal infiltrate or at the site of active sprout tip growth, but 
older sprout stalk endothelium was CD34+. Several recent studies ${ }^{15,17,26,41}$ suggest an unlikely role for CD34+ hemaopoeitic progenitor cells in various angiogenic models, however, the contribution of hematopoietic progenitors to angiogenesis remains controversial $^{42,43}$. At day 7, the majority of new vessels expressed the mature pericyte markers NG2 and $\alpha$-SMA. In future studies, markers for earlier, pericyte progenitor cells ${ }^{29,30}$ can be further explored to determine their morphology and distribution within the inflammatory infiltrate.

The processes involved in the angiogenic cascade are numerous and complex, and many detailed mechanisms remain to be elucidated in our model. The specific relationship of the early tunnels to later sprout invasion remains to be determined. Also, while the appearance of several cell populations (eg., mature macrophages, dendritic cells, pericytes) was delayed relative to the early infiltration of $\mathrm{CD} 11 \mathrm{~b}+$ myeloid cells, the contribution of these populations to the sprouting process could be important and remains to be investigated. In this work, we introduced a technique to examine angiogenic events occurring in single vessels in vivo, and demonstrated its use in characterizing the process of angiogenic sprouting at the cellular level. The major findings in this work were: i) early stromal tunneling by rounded and spindle-shaped myeloid-lineage cells; ii) a tripling of limbal vessel diameter preceding sprouting ; iii) an intimate association between myeloid cells and advancing sprouts; iv) incorporation of myeloid cells into sprout walls; and v) open-ended sprouts ejecting material into the ECM. The use of non-invasive imaging instrumentation approved for human clinical use, and the initial results presented, suggest that this technique may expand the experimental and eventual clinical possibilities of studying angiogenic processes at the cellular level in vivo. 


\section{References}

1. Ebrahem Q, Chaurasia S, Vasanji A et al. Cross-talk between vascular endothelial growth factor and matrix metalloproteinases in the induction of neovascularization in vivo. Am J Pathol. 2010;176;496-503.

2. Kilarski W W, Samolov B, Petersson L, Kvanta A, Gerwins P. Biomechanical regulation of blood vessel growth during tissue vascularization. Nature Med. 2009;15:6:657-664.

3. Takahashi T, Kalka $\mathrm{C}$, Masuda $\mathrm{H}$ et al. Ischemia- and cytokine-induced mobilization of bone marrow-derived endothelial progenitor cells for neovascularization. Nature Med 1999;5:4:434-438.

4. Gimbrone Jr. M.A, Cotran R.S, Leapman S.B, Folkman J. Tumor growth and neovascularization: an experimental model using the rabbit cornea. J. Natl. Cancer Inst. 1974;52:413-427.

5. Regenfuss B, Bock F, Parthasarathy A, Cursiefen C. Corneal (lymph)angiogensis - From bedside to bench and back: A tribute to Judah Fokman. Lymph Res and Biol. 2008;6:191-201.

6. Streilein JW. New thoughts in the immunolgy of corneal transplantation. Eye 2003;17:943948.

7. Cursiefen C, Kruse F. New aspects of angiogenesis in the cornea. Essentials Ophthalmol. 2006; 83-99.

8. Dastjerdi MH, Saban DR, Okanobo A et al. Effects of topical and subconjunctival bevacizumab in high-risk corneal transplant survival. Invest Ophthalmol Vis Sci. 2010;51:2411-7.

9. Wuest T R, Carr D.J.J. VEGF-A expression by HSV-1-infected cells drives corneal lymphangiogenesis. J Exp Med. 2010;207:1:101-115.

10. Kaye S, Choudhary A. Herpes simplex virus keratitis. Prog Retin Eye Res. 2006;25:355-380.

11. Zheng M, Deshpande S, Lee S, Ferrara N, Rouse B.T. Contribution of vascular endothelial growth factor in the neovascularization process during the pathogenesis of herpetic stromal keratitis. Journal of Virology. 2001;70:9828-9835.

12. Ausprunk DH, Folkman J. Migration and proliferation of endothelial cells in preformed and newly formed blood vessels during tumor angiogenesis. Microvasc Res 1977;14:53-65.

13. Bourghardt Peebo B, Fagerholm P, Traneus Röckert C, Lagali N. Cellular-level characteristics of lymph vessels in live, unlabeled corneas by in vivo confocal microscopy. Invest Ophthalmol Vis Sci. 2010;51:830-835.

14. Heil M, Ziegelhoeffer T, Pipp F et al. Blood monocyte concentration is critical for enhancement of collateral artery growth. Am J Physiol Heart Circ Physiol. 2002;H2411H2419. 
15. Kim S-J, Kim J-S, Papadopoulos J et al. Circulating monocytes expressing CD31Implications for acute and chronic angiogenesis. Am J Pathol. 2009;174:1972-1980.

16. Frid M, Brunetti J, Burke D L et al. Hypoxia-induced pulmonary vascular remodeling requires recruitment of circulating mesenchymal precursors of a monocyte/macrophage lineage. Am J Pathol. 2006;168:659-669.

17. Rehman J, Li J, Orschell C M, March K L. Peripheral blood "endothelial progenitor cells" are derived from monocyte/macrophages and secrete angiogenic growth factors. Circulation 2003;107:1164-1169.

18. Sunderkötter C, Steinbrink K, Goebeler M, Bhardwaj R, Sorg C. Macrophages and angiogenesis. J Leukocyte Biol. 1994;55:410-422.

19. Moldovan NI, Goldschmidt-Clermont PJ, Parker-Thornburg J, Shapiro SD, Kolattukudy PE. Contribution of monocytes/macrophages to compensatory neovascularization - the drilling of metalloelastase-positive tunnels in ischemic myocardium. Circ Res. 2000;87:378-384.

20. Capoccia B, Shepherd R M, Link D C. G-CSF and AMD3100 mobilize monocytes into the blood that stimulate angiogenesis in vivo through a paracrine mechanism. Blood 2006;108:2438-2444.

21. Cursiefen C, Chen L, Borges L et al. VEGF-A stimulates lymphangiogenesis and hemangiogenesis in inflammatory neovascularization via macrophage recruitment. J Clin Invest. 2004;113:1040-1050.

22. Anghelina M, Krishnan P, Moldovan L, Moldovan N I. Monocytes/macrophages cooperate with progenitor cells during neovascularization and tissue repair - conversion of cell columns into fibrovascular bundles. Am J Pathol. 2006;168:529-541.

23. Nénan S, Boichot E, Planquois J-M et al. Effects of depletion of neutrophils or macrophages on the inflammatory response induced by metalloelastase (MMP-12) in the mice airways. Eur J Pharmacol. 2008;579:374-381.

24. Schmeisser A, Garlichs C D, Zhang H et al. Monocytes coexpress endothelial and macrophagocytic lineage markers and form cord-like structures in Matrigel under angiogenic conditions. Cardiovasc Res. 2001;49:671-680.

25. Zhao Y, Glesna D, Huberman E. A human peripheral blood monocyte-derived subset acts as a pluripotent stem cell. PNAS 2003;100:2426-2431.

26. Fujiyama S, Amano K, Uehira K et al. Bone marrow monocyte lineage cells adhere on injured endothelium in a monocyte chemoattractant protein-1-dependent manner and accelerate reendothelialization as endothelial progenitor cells. Circ Res. 2003;93:980-989.

27. Fernandez Pujol B, Lucibello F C, Gehling U M et al. Endothelial-like cells derived from human CD14 positive monocytes. Differentiation 2000; 65:287-300. 
28. Altman DG, Bland JM. Statistical methods for assessing agreement between two methods of clinical measurements. Lancet 1986;327:307-310.

29. Ozerdem U, Alitalo K, Salven P, Li A. Contribution of bone marrow-derived pericyte precursor cells to corneal vasculogenesis. Invest Ophthalmol Vis Sci 2005;46:3502-3506.

30. Lamagna $\mathrm{C}$, Bergers $\mathrm{G}$. The bone marrow constitutes a reservoir of pericyte progenitors. $J$ Leukoc Biol 2006;80:677-681.

31. Li Z, Burns A R, Smith W. Two waves of neutrophil emigration in response to corneal epithelial abrasion: distinct adhesion molecule requirements. Invest Ophthalmol Vis Sci. 2006;47:1947-1955.

32. Zhu S-N, Dana R. Expression of cell adhesion molecules on limbal and neovascular endothelium in corneal inflammatory neovascualrization. Invest Ophthalmol Vis Sci. 1999;40:1427-1434.

33. Sunderkötter C, Beil W, Roth J, Sorg C. Cellular events associated with inflammatory angiogensis in the mouse cornea. Am J Pathol. 1991;138:931-9.

34. Wagener E M, Sánchez J, McClintock Y, Jenkins J, Moldobaeva A. Inflammation and ischemia-induced lung angiogenesis. Am J Physiol Lung Cell Mol Physiol. 2008;294:L351L357.

35. Arroyo A G, Iruela-Arispe. Extracellular matrix, inflammation, and the angiogenic response. Cardiovasc Res 2010; E-pub ahead of print.

36. Costa C, Incio J, Soares R. Angiogenesis and chronic inflammation: cause or consequence? Angiogenesis 2007;10:149-166.

37. Maus UA, Waelsch K, Kuziel WA et al. Monocytes are potent facilitators of alveolar neutrophil emigration during lung inflammation: role of the CCL2-CCR2 axis. J Immunol. 2003;170:3273-3278.

38. Anghelina M, Krishnan P, Moldovan L, Moldovan NI. Monocytes and macrophages form branched cell columns in matrigel: Implication for a role in neovascularization. Stem cell Develop. 2004;13:665-676.

39. Maruyama K, Masaaki I, Cursiefen C et al. Inflammation-induced lymphangiogenesis in the cornea arises from CD11b-positive macrophages. J Clin Invest. 2005;115:2363-2372.

40. Gerhardt H, Golding M, Fruttiger M et al. VEGF guides angiogenic sprouting utilizing endothelial tip cell filopodia. J Cell Biol. 2003;23:1163-1177.

41. Bailey A, Willenbring H, Jiang S et al. Myeloid lineage progenitors give rise to vascular endothelium. PNAS 2006;103:13156-13161. 
42. Krenning G, van Luyn M J A, Harmsen M C. Endothelial progenitor cell-based neovascularization: implications for therapy. Trends Mol Med. 2009;15:180-189.

43. Horrevoets A J G. Angiogenic monocytes - another colorful blow to endothelial progenitors. Am J Path.2009;5:1594-1596 
Movie Captions:

Movie S1:

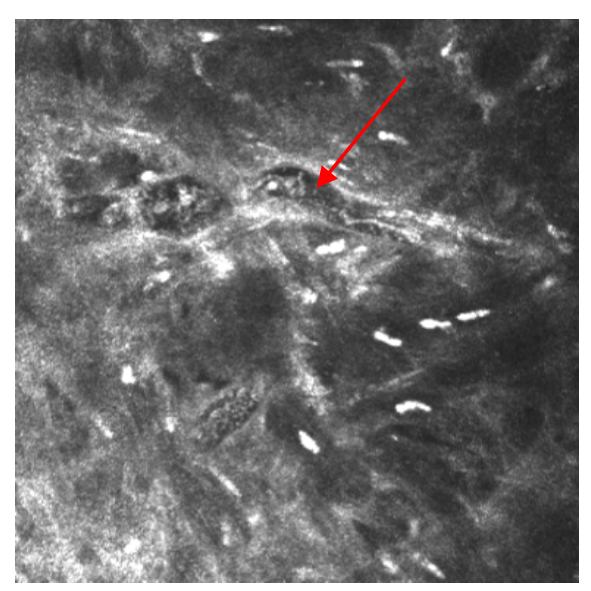

New sprout at Day 4 (arrow), being perfused with blood components and cellular elements.

Note that the perfused sprout is temporarily isolated from flowing blood. 
Figure Captions:

Figure 1: Extravasation of inflammatory cells from limbal vessels. (A) Extravasated inflammatory cells (arrow) from a limbal vessel at 6h. (B) At 6h, a hypo-reflective tunnel in the stromal ECM is occupied by a leading cell (red arrow) and trailing cells (white arrow). Cells originate from a limbal vessel (asterisk). (C, D) CD11b+ cells enter the stroma within tunnels. (E) Cells reaching the suture area (asterisk) at day 1 form "string of pearls" configurations (arrows). (F) Stromal tunnels (hyporeflective, arrows) are occupied by spindleshaped cells. Scale bar $=50 \mu \mathrm{m}$.

Figure 2. Myeloid-lineage cells within the inflammatory infiltrate. (A, B) Inflammatory cells are CD11b+CD45+. (C) Scattered CD11b-CD11c+ (green) and CD11b+CD11c+ (yellow) dendritic cells were found at day 2 in the limbal region, whereas only CD11b+CD11c- cells (red) appeared in linear configurations (arrows). (D) The population of CD11c+ cells appeared randomly distributed within the stroma. Scale bar $=50 \mu \mathrm{m}$.

Figure 3. Delayed appearance of mature macrophages. (A, B) CD11b+Ki-M2R+ mature macrophages (yellow, green) are sparse in the stroma at day 2. (C) Cells near the suture (S) at day 7 had an irregular shape and hypo-reflective cell nucleus in vivo (red arrows), that corresponded to (D) CD11b+KiM2R+ mature macrophages (red arrow). Scale bar $=50 \mu \mathrm{m}$.

Figure 4. Time-lapse in vivo images of the same limbal vessel 0 - 4 days after suture placement. (A - E). On day 4, budding and sprouting is evident (E, asterisk, magnified view in inset). Scale bar $=50 \mu \mathrm{m}$.

Figure 5. In-vivo quantification of inflammatory cell extravasation and limbal vessel diameter over a four day period. (A-C) Quantitative analysis of the number of infiltrating inflammatory cells surrounding the same vessel. Each plot depicts data from a single cornea. 
Data points represent mean values from two observers, and error bars indicate the $95 \%$ interobserver limits of agreement. (D-F) Box plots of limbal vessel diameter over four days in a given cornea. Box lines indicate median value, borders represent $1^{\text {st }}$ and $3^{\text {rd }}$ quartiles, and whiskers represent $5^{\text {th }}$ and $95^{\text {th }}$ percentiles. Peak vessel diameter was significantly greater than the value at day 1 in all corneas $(\mathrm{P}<0.001)$. Vessel diameter decreased after peaking.

Figure 6. In vivo/ex vivo analysis of the same vascular buds arising from limbal vessels at day 2. In vivo $(\mathbf{A}, \mathbf{C}, \mathbf{E})$ and immunofluorescent $(\mathbf{B}, \mathbf{D}, \mathbf{F})$ images of the same parent limbal vessels at day 2. At the time of maximal limbal vessel expansion, CD11b-CD31+ vascular buds (A-F, arrows) emerge from the vessel wall (region marked by asterisk is magnified in inset). Stromally-located cells are CD11b+CD31-. Scale bar $=50 \mu \mathrm{m}$.

Figure 7. Time-lapse in vivo analysis of capillary sprout emergence from a parent limbal vessel. Intense inflammatory cell infiltration at day 1 (A) subsides at day 2 , when the vessel has expanded and formed vascular buds (B, red arrowheads). At day 3, perfused sprouts (C, white arrows) are present in the region of earlier buds (red arrowheads). Scale bar $=50 \mu \mathrm{m}$.

Figure 8. Perfusion characteristics of capillary sprouts at day 4-7. (A - D) Capillary sprouts contained a slow-moving fluid harboring round, hyper-reflective cells (red and white arrowheads). (A-E) Long cord-like structures were also present within sprouts (white arrows), in some cases appearing to be ejected into the stroma from the sprout tip (B, C). Sprout tips were open-ended (B-D, yellow arrows). Hyper-reflective angiogenic vessel loops (F, green asterisks) were perfused with freely-flowing, erythrocyte-rich blood, bypassing erythrocyte-poor capillary sprouts $(\mathbf{F}$, arrows). Scale bar $=50 \mu \mathrm{m}$.

Figure 9. An intimate association of CD11b+ cells with growing sprout tips. (A-F) At day $4-$ 7, spindle-shaped cells (white arrows) align within tunnels and extend beyond the sprout tip 
(red arrowheads) in the direction of the suture. (C) Spindle-shaped cells sometimes incorporated into sprout vessel walls (yellow arrows). (D-F) CD11b+ cells were closely associated with sprout tips and some appeared to be located within vessel walls (white arrows). (G-I) In some cases, CD31+ sprout tips were attached to cells strongly co-staining $\mathrm{CD} 11 \mathrm{~b}+\mathrm{CD} 31+$ (arrows). Fine CD11b-CD31+ extensions emanated from sprout tips (white arrowhead). Scale bar $=50 \mu \mathrm{m}$.

Figure 10. Expression of CD11b and mature endothelial markers at day 7. (A - C) Mature vessel stalks at day 7 are CD11b-CD31+ while surrounding inflammatory cells are CD11b+CD31-. Scale bar $=50 \mu \mathrm{m}$.

Figure 11. Evidence of pericyte presence on mature corneal vessels at day 7. (A - C) The same vessels were located in vivo and ex vivo (asterisk indicates the same location). Mature, perfused vessels were NG2+ at day $7(\mathbf{C})$, but surrounding spindle-shaped cells observed around the same vessels in vivo were CD31-NG2-. (D, E) Mature vessels were $\alpha-S M A+$ on day 7 , but surrounding cells observed in vivo were $\alpha$-SMA-. (F) On some vessel stalks at day 7, CD11b+ cells (arrows) were observed in close apposition to vessel walls, possibly representing pericyte precursors. Scale bar $=50 \mu \mathrm{m}$. 

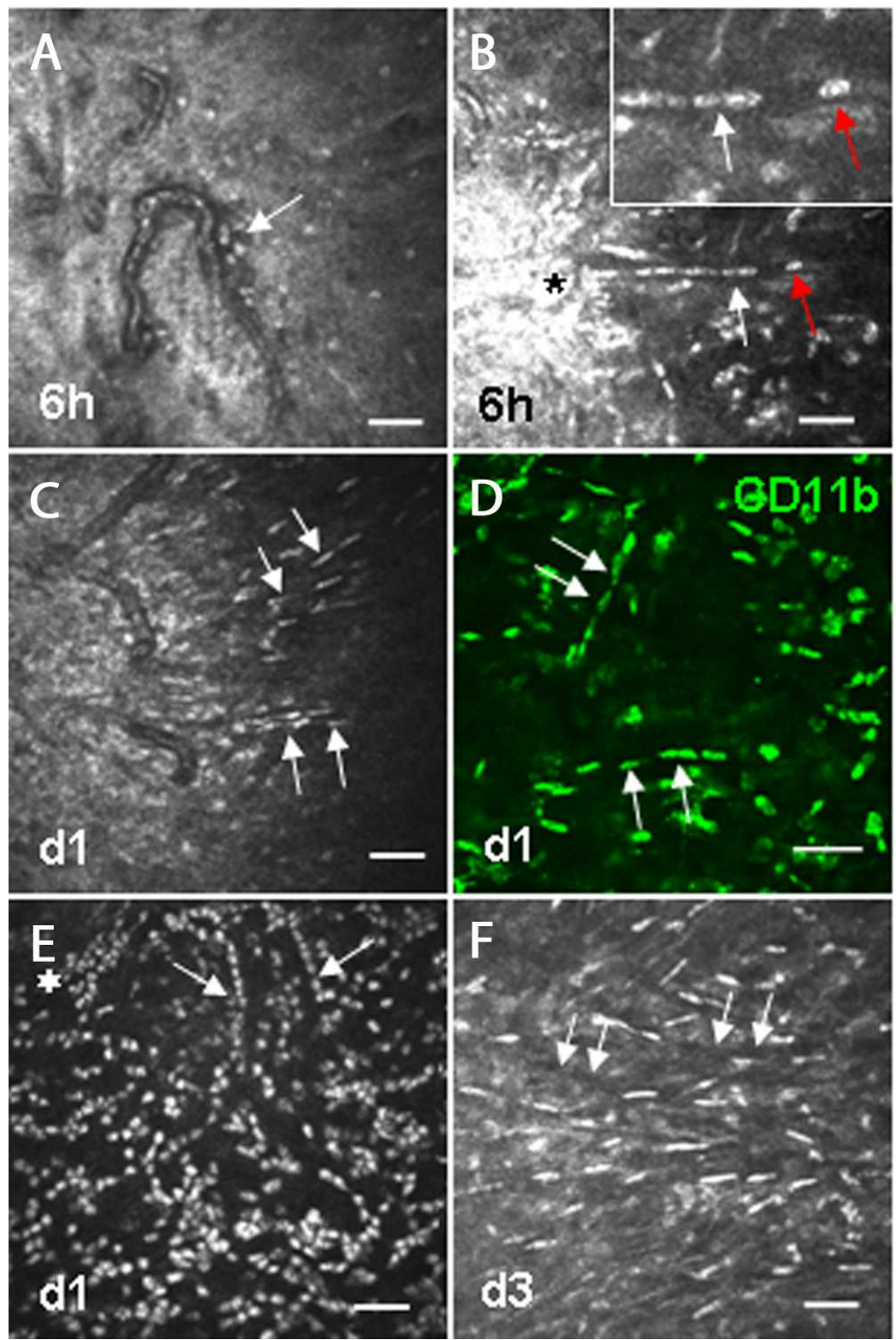

Figure 1: Extravasation of inflammatory cells from limbal vessels. (A) Extravasated inflammatory cells (arrow) from a limbal vessel at 6h. (B) At 6h, a hypo-reflective tunnel in the stromal ECM is occupied by a leading cell (red arrow) and trailing cells (white arrow). Cells originate from a limbal vessel (asterisk). (C, D) CD11b+ cells enter the stroma within tunnels. (E) Cells reaching the suture area (asterisk) at day 1 form "string of pearls" configurations (arrows). (F) Stromal tunnels (hyporeflective, arrows) are occupied by spindle-shaped cells. Scale bar $=50 \mu \mathrm{m}$. 

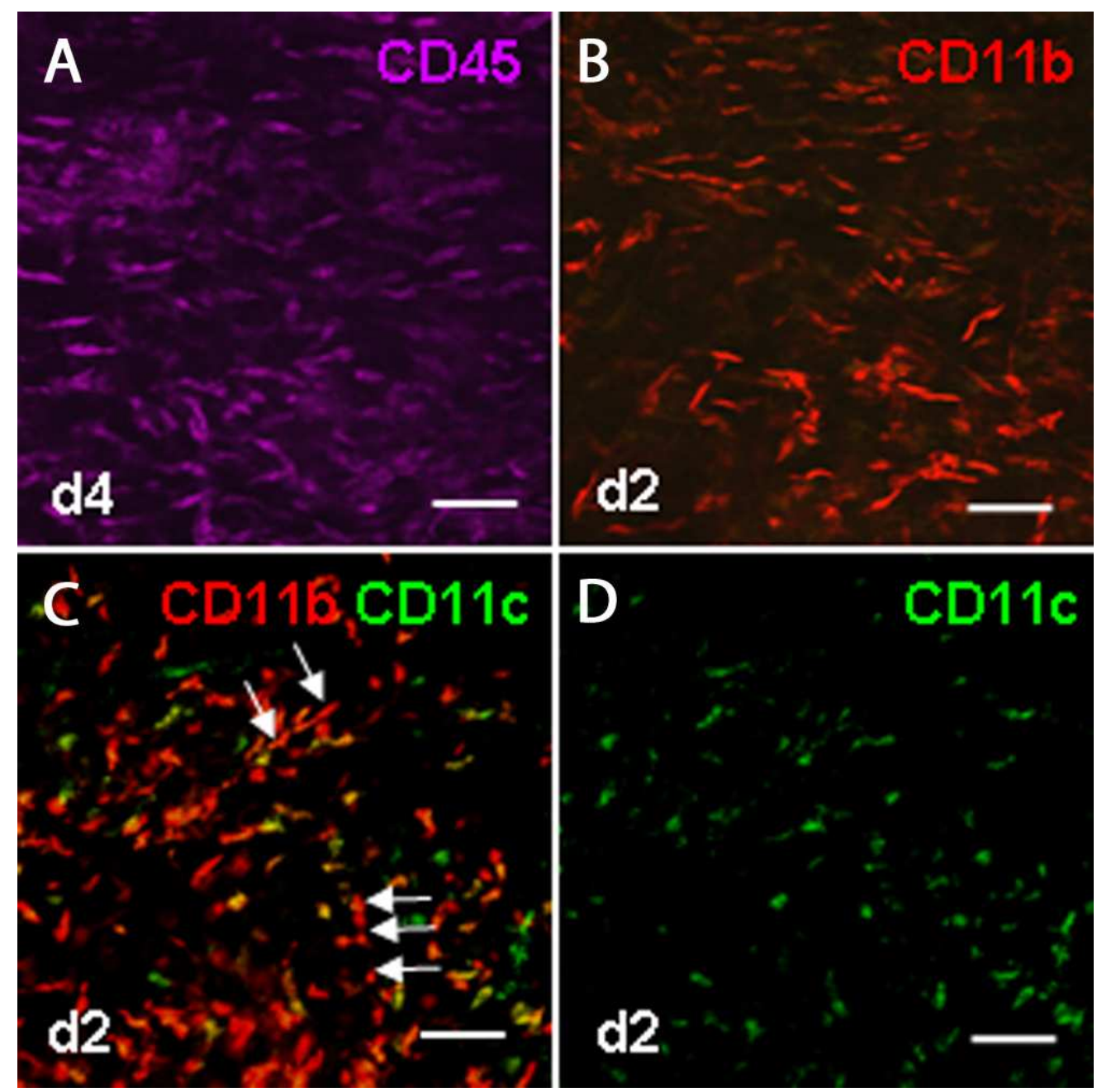

Figure 2. Myeloid-lineage cells within the inflammatory infiltrate. (A, B) Inflammatory cells are CD11b+ CD45+. (C) Scattered CD11b-CD11c+ (green) and CD11b+CD11c+ (yellow) dendritic cells were found at day 2 in the limbal region, whereas only CD11b+CD11c-cells (red) appeared in linear configurations (arrows). (D) The population of CD11C+ cells appeared randomly distributed within the stroma. Scale bar $=50 \mu \mathrm{m}$. $84 \times 84 \mathrm{~mm}(300 \times 300 \mathrm{DPI})$ 


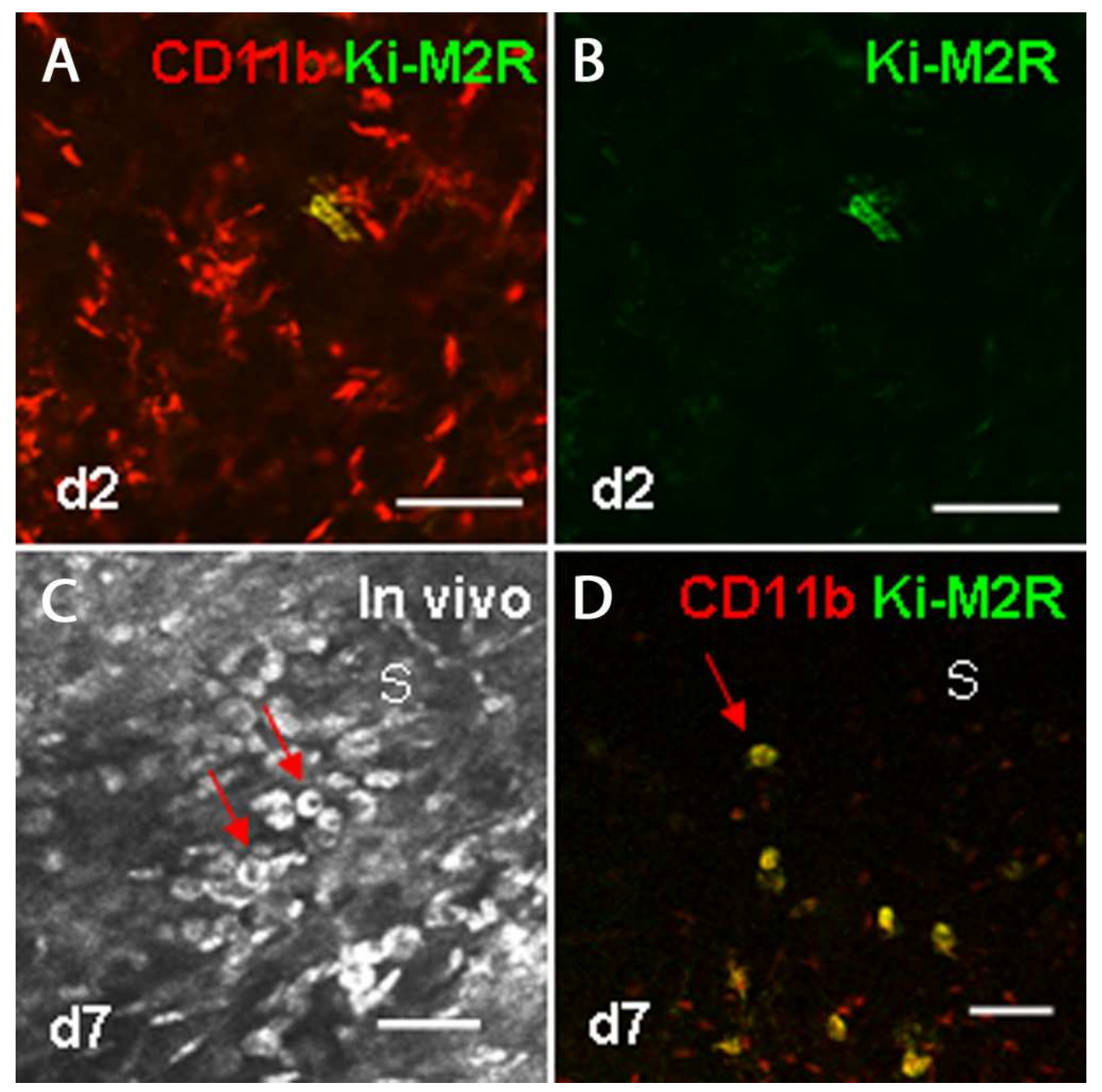

Figure 3. Delayed appearance of mature macrophages. $(A, B) C D 11 b+K i-M 2 R+$ mature macrophages (yellow, green) are sparse in the stroma at day 2. (C) Cells near the suture (S) at

day 7 had an irregular shape and hypo-reflective cell nucleus in vivo (red arrows), that corresponded to (D) CD11b+KiM2R+ mature macrophages (red arrow). Scale bar $=50 \mu \mathrm{m}$. $84 \times 84 \mathrm{~mm}(300 \times 300$ DPI $)$ 


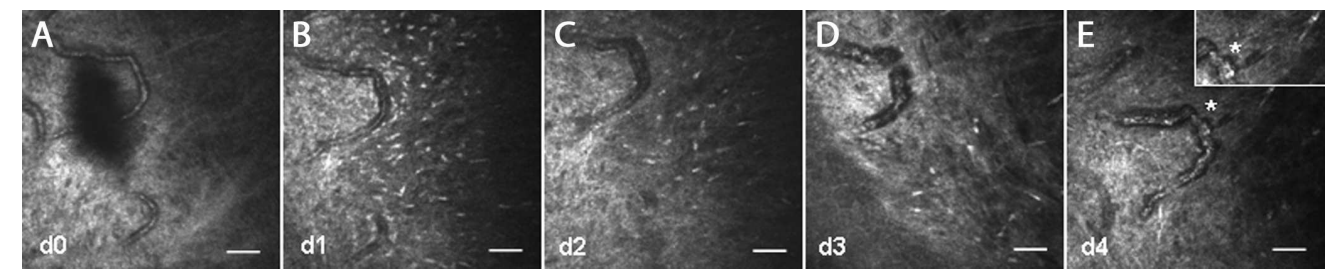

Figure 4. Time-lapse in vivo images of the same limbal vessel $0-4$ days after suture placement. (A - E). On day 4, budding and sprouting is evident ( $E$, asterisk, magnified view in inset). Scale bar = $50 \mu \mathrm{m}$.

$175 \times 34 \mathrm{~mm}(300 \times 300 \mathrm{DPI})$ 


\section{Inflammatory cells}
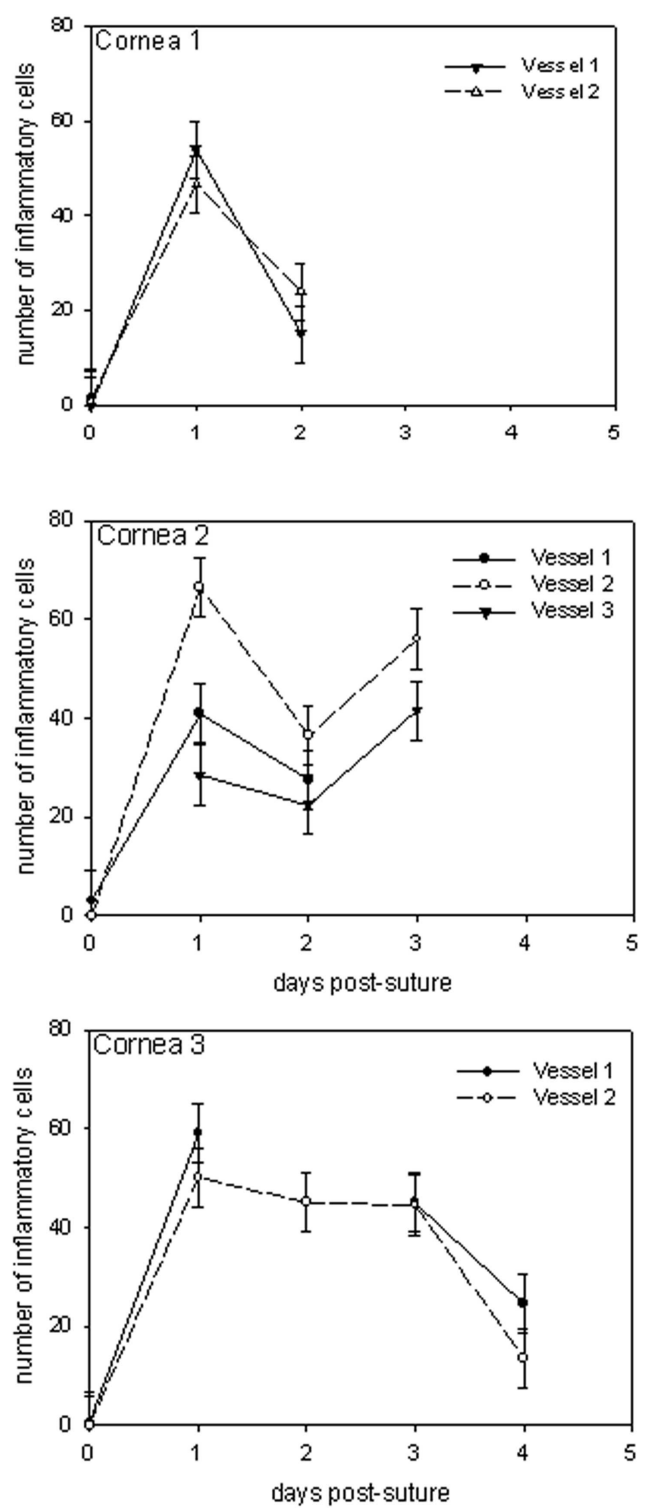
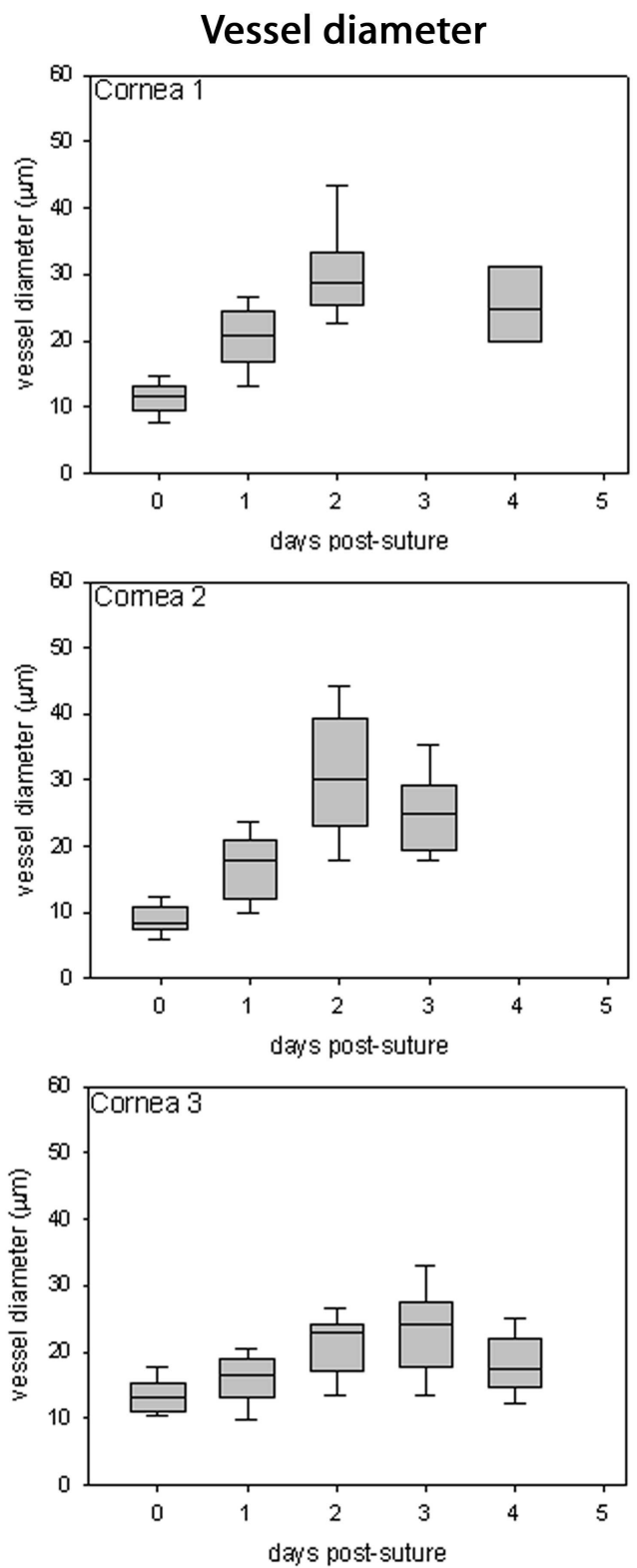

Figure 5. In-vivo quantification of inflammatory cell extravasation and limbal vessel diameter over a four day period. (A-C) Quantitative analysis of the number of infiltrating inflammatory cells surrounding the same vessel. Each plot depicts data from a single cornea. Data points represent mean values from two observers, and error bars indicate the $95 \%$ inter-observer limits of agreement. (D-F) Box plots of limbal vessel diameter over four days in a given cornea. Box lines indicate median value, borders represent 1 st and 3rd quartiles, and whiskers represent 5 th and 95th percentiles. Peak vessel diameter was significantly greater than the value at day 1 in all corneas $(P<0.001)$. Vessel diameter decreased after peaking. $127 \times 153 \mathrm{~mm}(600 \times 600 \mathrm{DPI})$ 


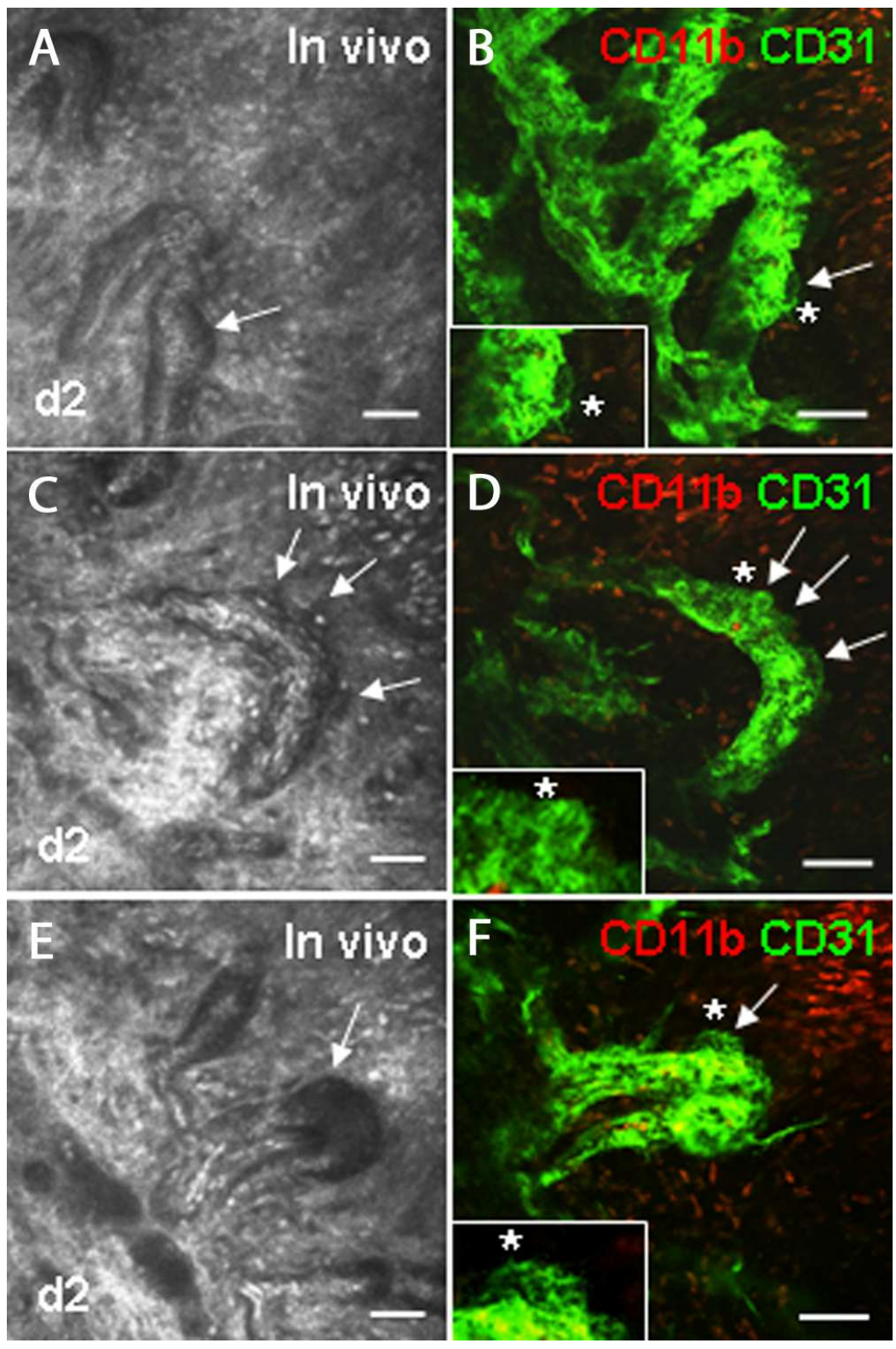

Figure 6. In vivo/ex vivo analysis of the same vascular buds arising from limbal vessels at day 2 . In vivo $(A, C, E)$ and immunofluorescent $(B, D, F)$ images of the same parent limbal vessels at day 2. At the time of maximal limbal vessel expansion, CD11b-CD31+ vascular buds (A-F, arrows) emerge from the vessel wall (region marked by asterisk is magnified in inset). Stromally-located cells are CD11b+CD31-. Scale bar $=50 \mu \mathrm{m}$. $84 \times 127 \mathrm{~mm}(300 \times 300 \mathrm{DPI})$ 

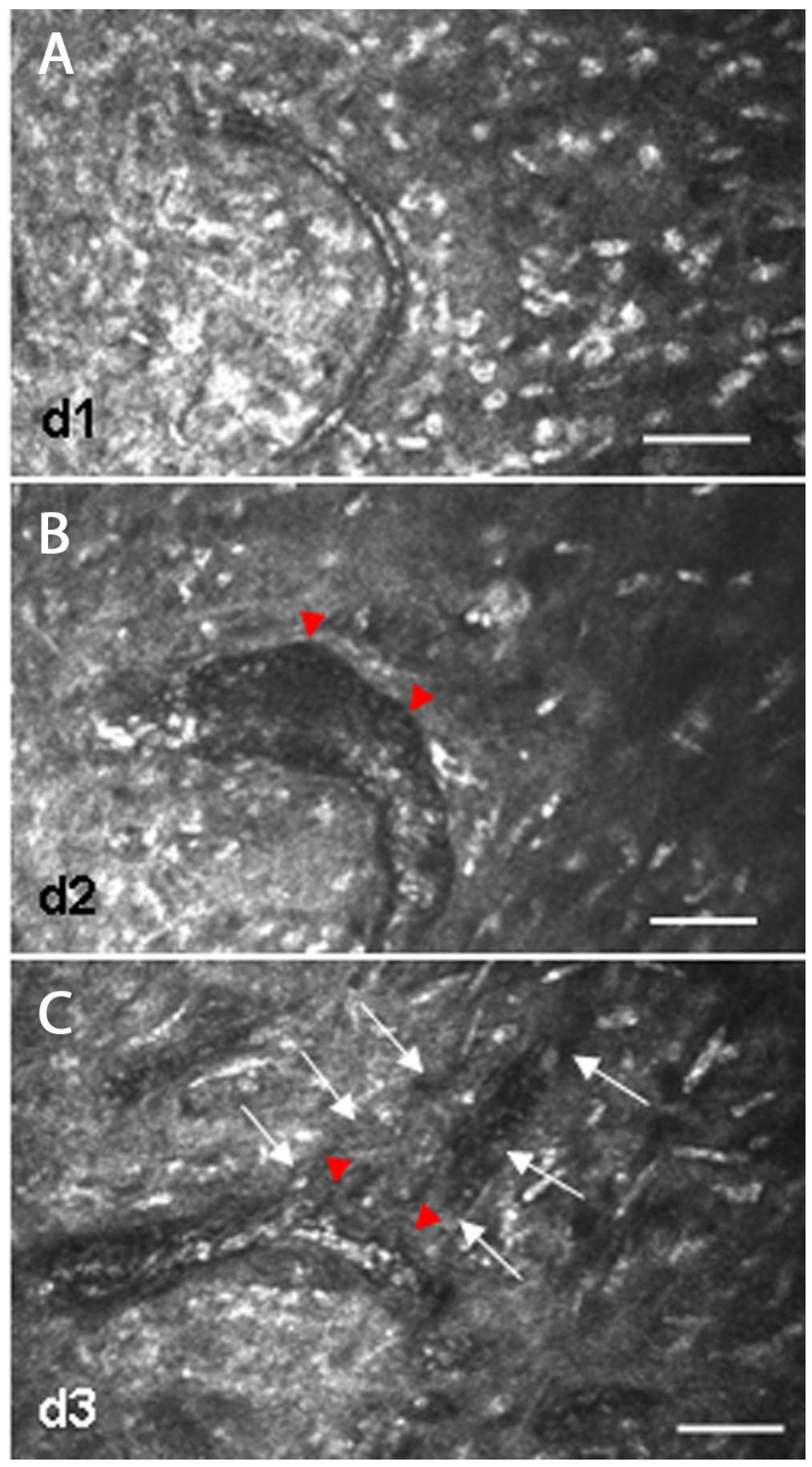

Figure 7. Time-lapse in vivo analysis of capillary sprout emergence from a parent limbal vessel. Intense inflammatory cell infiltration at day $1(A)$ subsides at day 2 , when the vessel has expanded and formed vascular buds ( $B$, red arrowheads). At day 3 , perfused sprouts ( $C$, white arrows) are present in the region of earlier buds (red arrowheads). Scale bar $=50 \mu \mathrm{m}$. $84 \times 153 \mathrm{~mm}(300 \times 300$ DPI $)$ 

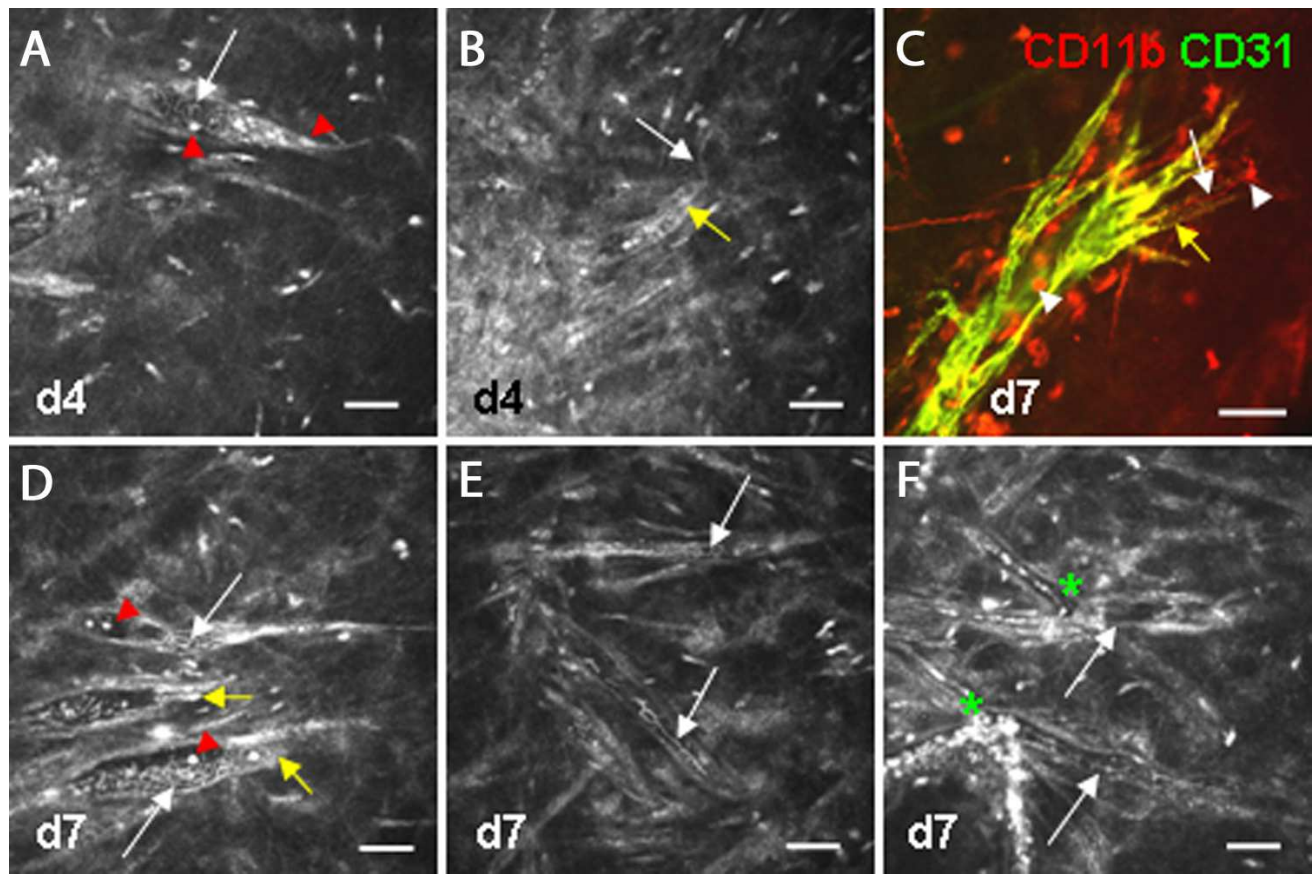

Figure 8. Perfusion characteristics of capillary sprouts at day $4-7$. (A - D) Capillary sprouts contained a slow-moving fluid harboring round, hyper-reflective cells (red and white arrowheads). (A-E) Long cord-like structures were also present within sprouts (white arrows), in some cases appearing to be ejected into the stroma from the sprout tip ( $B, C)$. Sprout tips were open-ended (B$D$, yellow arrows). Hyper-reflective angiogenic vessel loops ( $F$, green asterisks) were perfused with freely-flowing, erythrocyte-rich blood, bypassing erythrocyte-poor capillary sprouts ( $F$, arrows). Scale bar $=50 \mu \mathrm{m}$. 

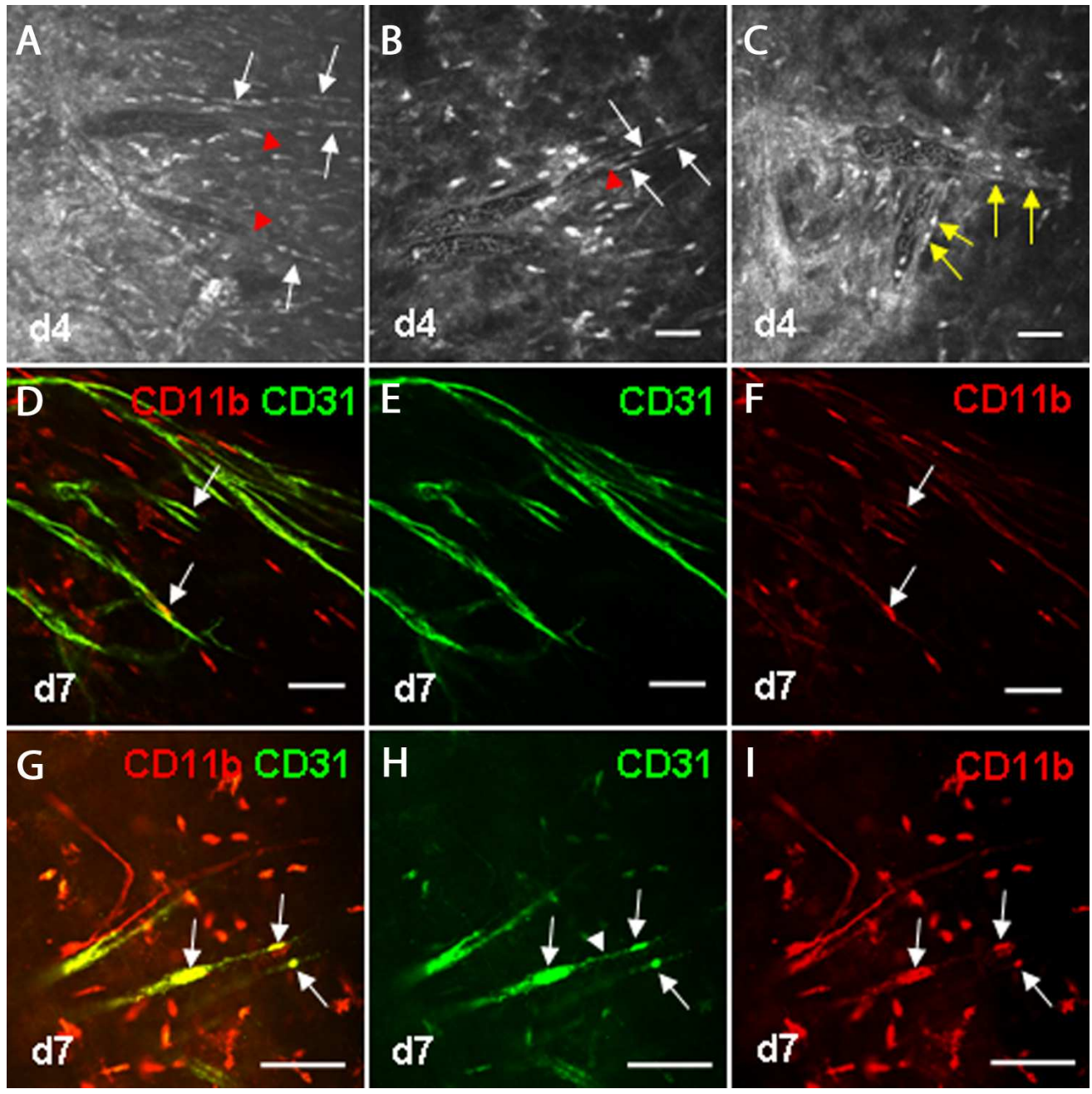

Figure 9. An intimate association of $C D 11 b+$ cells with growing sprout tips. (A-F) At day $4-7$, spindle-shaped cells (white arrows) align within tunnels and extend beyond the sprout tip (red arrowheads) in the direction of the suture. (C) Spindle-shaped cells sometimes incorporated into sprout vessel walls (yellow arrows). (D-F) CD11b+ cells were closely associated with sprout tips and some appeared to be located within vessel walls (white arrows). (G-I) In some cases, CD31+ sprout

tips were attached to cells strongly co-staining CD11b + CD $31+$ (arrows). Fine CD11b-CD31+ extensions emanated from sprout tips (white arrowhead). Scale bar $=50 \mu \mathrm{m}$.

$127 \times 127 \mathrm{~mm}(300 \times 300 \mathrm{DPI})$ 

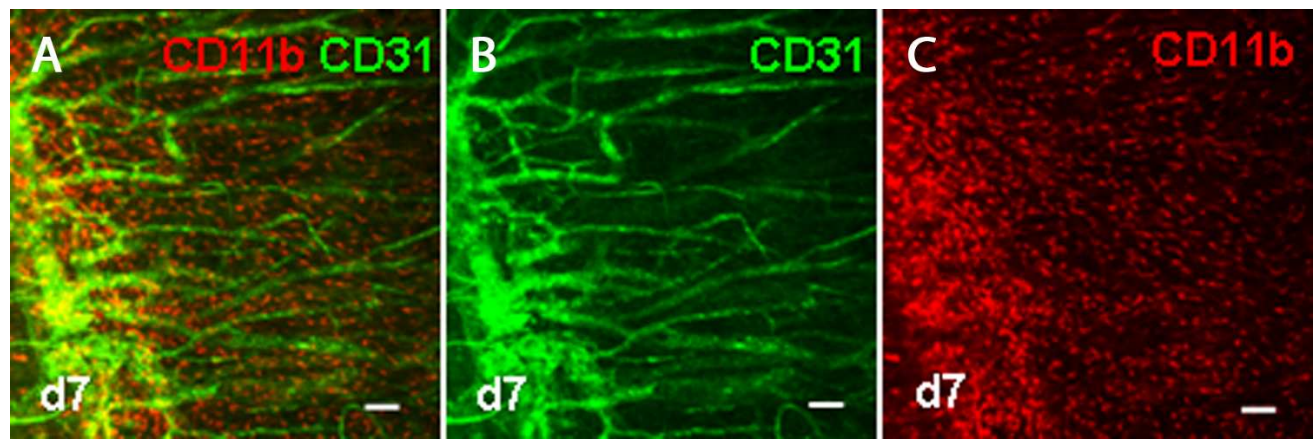

Figure 10. Expression of $C D 11 \mathrm{~b}$ and mature endothelial markers at day 7. (A - C) Mature vessel stalks at day 7 are CD11b-CD31+ while surrounding inflammatory cells are CD11b+CD31-. Scale bar $=50 \mu \mathrm{m}$.

$127 \times 41 \mathrm{~mm}(300 \times 300 \mathrm{DPI})$ 

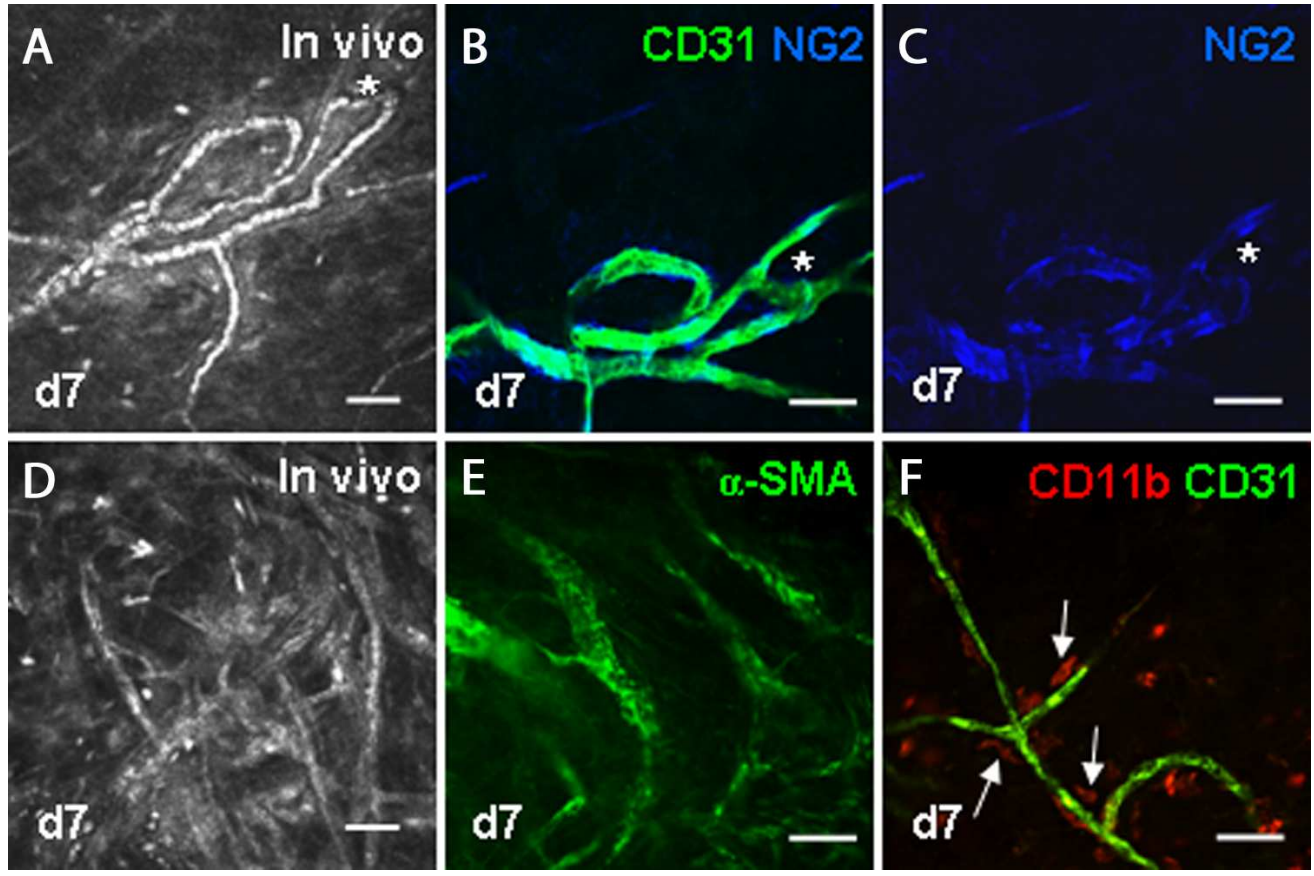

Figure 11. Evidence of pericyte presence on mature corneal vessels at day 7. (A - C) The same vessels were located in vivo and ex vivo (asterisk indicates the same location). Mature, perfused vessels were NG2+ at day 7 (C), but surrounding spindle-shaped cells observed around the same vessels in vivo were CD31-NG2-. (D, E) Mature vessels were a-SMA+ on day 7, but surrounding cells observed in vivo were a-SMA-. (F) On some vessel stalks at day 7, CD11b+ cells (arrows) were observed in close apposition to vessel walls, possibly representing pericyte precursors. Scale bar $=$ $50 \mu \mathrm{m}$.

$127 \times 84 \mathrm{~mm}(300 \times 300 \mathrm{DPI})$ 